\title{
Is there a role for thoracic aortic calcium to fine-tune cardiovascular risk prediction?
}

\author{
Marc Hartmann • Clemens von Birgelen
}

Received: 5 April 2012/Accepted: 12 April 2012/Published online: 24 April 2012

(C) The Author(s) 2012. This article is published with open access at Springerlink.com

\begin{abstract}
Screening asymptomatic subjects to streamline measures for the prevention of cardiovascular events remains a major challenge. The established primary prevention risk-scoring methods use equations derived from large prospective cohort studies, but further fine-tuning of cardiovascular risk assessment remains important as $25 \%$ of individuals with low estimated risk may experience cardiac events. Independent studies provided evidence that extended risk assessment using coronary artery calcium quantification may improve risk stratification as it can lead to reclassification of persons at increased risk. Particularly in intermediate-risk subjects, coronary artery calcium scoring can help to correctly identify individuals at highest risk. Data on the extent of calcification of the ascending and descending thoracic aorta might be useful for additional cardiovascular risk stratification. Future analyses and studies will be required to answer the question of whether the implementation of such data may allow further finetuning of cardiovascular risk prediction in specific subpopulations-for instance in women or men with an increased risk of stroke and/or symptomatic peripheral vascular disease.
\end{abstract}

Keywords Thoracic aortic calcification . Coronary artery calcium - Computed tomography .

Risk prediction $\cdot$ Calcium score

\footnotetext{
M. Hartmann · C. von Birgelen ( $₫)$

Department of Cardiology, Thoraxcentrum Twente,

Medisch Spectrum Twente, Haaksbergerstraat 55,

7513 ER Enschede, The Netherlands

e-mail: c.vonbirgelen@mst.nl

C. von Birgelen

MIRA Institute, University of Twente, Enschede,

The Netherlands
}

Cardiovascular events are important causes of death and disability. Primary prevention to lower the incidence of such events is of paramount importance. Nevertheless, screening asymptomatic subjects to streamline preventive measures remains a major challenge [1]. Classical cardiovascular risk factors such as age, gender, cholesterol levels, blood pressure, and smoking are traditionally employed to assess the individual risk status, to trigger lifestyle modification, and to guide drug prescription in order to prevent cardiovascular events. Ideally, a predictor of the overall risk of cardiovascular events should be based on a robust multifactorial model [2-5]. The established primary prevention risk-scoring methods use equations derived from large prospective cohort studies, such as the European Systematic Coronary Risk Evaluation Project (SCORE) [2], the German Prospective Cardiovascular Münster (PROCAM) study [3], and the US-American Framingham Heart and Offspring Studies [4, 5]. These estimated risk values even appear to be related to coronary plaque progression rates [7]. Risk prediction models may be most favorable for the continent, subcontinent, or even country, from which an underlying data set is derived, which is the reason for the current coexistence of several cardiovascular risk scores [2-5]. Current guidelines on dislipidemia use the estimated individual risk from such scoring systems to guide lipid-lowering therapy with statins in primary cardiovascular prevention [6]. The abovementioned facts underline the importance of prospective cohort studies to gain information about population-based cardiovascular event risks, which is required to develop evidence-based clinical guidelines that have major impact on our daily clinical practice.

Fine-tuning of cardiovascular risk assessment remains important as $25 \%$ of individuals with low estimated risk may experience cardiac events [1]. Independent studies 
provided evidence that extended risk assessment using coronary artery calcium (CAC) quantification may improve risk stratification as it can lead to reclassification of persons at increased risk [8-12]. One example of such large, population-based cohort studies is the Heinz Nixdorf Recall Study (4814 participants from the Ruhr metropolitan area in Germany), which investigates the ability of subclinical CAC quantification with electron-beam computed tomography scanning to predict the risk of major cardiovascular events at five-year follow-up above and beyond traditional cardiovascular risk factors $[1,11,13]$. This study demonstrated that a higher cardiovascular risk burden was associated with higher CAC scores and that CAC scoring improved risk stratification, discrimination, and reclassification [1, 11]. Particularly in intermediate-risk subjects, CAC scoring can help to correctly identify individuals at highest risk, which might contribute to reducing the number of coronary events in the general population [1, 11]. A representative US-American population, the Multi-Ethnic Study of Atherosclerosis (MESNA), also demonstrated an incremental prognostic value of absolute CAC scores over several traditional cardiovascular risk factors [14].

In the current issue of the journal, Raimund Erbel and his coworkers present interesting thoracic aortic calcification (TAC) data derived from the Heinz Nixdorf Recall cohort study [15]. The extent of calcification of the ascending and descending thoracic aorta, as determined with electron-beam computed tomography, was significantly associated with CAC burden [15]. While TAC largely shared cardiovascular risk factors with coronary artery disease, TAC was independently related to CAC [15].

In fact, these data from a general population in Western Europe [15] are very welcome. Data on TAC in large, general populations are scarce and were previously merely available from US-American populations [16-19]. Wong et al. studied in 2303 asymptomatic participants the ability of CAC and TAC to predict coronary heart disease and cardiovascular events and found that CAC, but not TAC, showed a strong relation with coronary heart disease and cardiovascular events [16]. However, in another USAmerican study, the MESNA study ( $\mathrm{n}=6814$ of four ethnic groups), TAC was found to be a strong predictor of CAC independent of cardiovascular risk factors [17, 18]. Santos et al. even demonstrated in a cohort of 8401 asymptomatic, predominantly white US-Americans, undergoing cardiac risk factor evaluation and scanning with electron-beam computed tomography, that the presence of TAC was associated with all-cause mortality, a relation that was independent of conventional cardiovascular risk factors and the presence of CAC [19]. In a Dutch high-risk population of 958 heavy smokers, Jacobs et al. found that $\mathrm{CAC}$ was a stronger predictor of cardiovascular events than TAC [20]. However, in this quite specific subpopulation of a lung cancer screening trial, TAC was stronger associated with vascular disease and events such as stroke as well as the occurrence of aortic aneurysms and occlusive peripheral arterial disease [20].

The present report from the Heinz Nixdorf Recall Study provides valuable computed age and gender-specific percentile curves for TAC in a Western European general population [15]. These percentiles may help to interpret individual thoracic calcification values and might be useful for additional cardiovascular risk stratification. Future analyses and studies will be required to answer the question of whether the implementation of these data may allow further fine-tuning of cardiovascular risk prediction in specific subpopulations-for instance in women or men with an increased risk of stroke and/or symptomatic peripheral vascular disease.

Conflict of interest Dr. Hartmann reports no conflict of interest. Dr. von Birgelen reports no conflict of interest relevant to this manuscript. $\mathrm{He}$ reports to be consultant to and to have received lecture fees or travel expenses from Abbott, Medtronic, and Boston Scientific; and he has received a speaker's honorarium from MSD.

Open Access This article is distributed under the terms of the Creative Commons Attribution License which permits any use, distribution, and reproduction in any medium, provided the original author(s) and the source are credited.

\section{References}

1. Erbel R, Möhlenkamp S, Moebus S, Heinz Nixdorf Recall Study Investigative Group et al (2010) Coronary risk stratification, discrimination, and reclassification improvement based on quantification of subclinical coronary atherosclerosis: the Heinz Nixdorf Recall study. J Am Coll Cardiol 56(17):1397-1406

2. Assmann G, Cullen P, Schulte H (2002) Simple scoring scheme for calculating the risk of acute coronary events based on the 10-year follow-up of the prospective cardiovascular Münster (PROCAM) study. Circulation 105:310-315

3. Conroy RM, Pyörälä K, Fitzgerald AP, for the SCORE project group et al (2003) Estimation of ten-year risk of fatal cardiovascular disease in Europe: the SCORE project. Eur Heart J 24: 987-1003

4. Anderson KM, Wilson PW, Odell PM et al (1991) An updated coronary risk profile: a statement for health professionals. Circulation 83:356-362

5. Grundy SM, Pasternak R, Greenland P et al (1999) Assessment of cardiovascular risk by use of multiple-risk-factor assessment equations: a statement for healthcare professionals from the American Heart Association and the American College of Cardiology. Circulation 100:1481-1492

6. Reiner Z, Catapano AL, De Backer G et al (2011) ESC/EAS Guidelines for the management of dyslipidaemias: the task force for the management of dyslipidaemias of the European Society of Cardiology (ESC) and the European Atherosclerosis Society (EAS). Eur Heart J 32(14):1769-1818

7. von Birgelen C, Hartmann M, Mintz GS et al (2004) Relationship between cardiovascular risk as predicted by established risk scores versus plaque progression as measured by serial 
intravascular ultrasound in left main coronary arteries. Circulation 110(12):1579-1585

8. Polonsky TS, McClelland RL, Jorgensen NW et al (2010) Coronary artery calcium score and risk classification for coronary heart disease prediction. JAMA 303(16):1610-1616

9. Greenland P, LaBree L, Azen SP et al (2004) Coronary artery calcium score combined with Framingham score for risk prediction in asymptomatic individuals. JAMA 291(2):210-215

10. Elias-Smale SE, Proença RV, Koller MT et al (2010) Coronary calcium score improves classification of coronary heart disease risk in the elderly: the Rotterdam study. J Am Coll Cardiol 56(17):1407-1414

11. Möhlenkamp S, Lehmann N, Moebus S et al (2011) Quantification of coronary atherosclerosis and inflammation to predict coronary events and all-cause mortality. J Am Coll Cardiol 57(13):1455-1464

12. Detrano R, Guerci AD, Carr JJ et al (2008) Coronary calcium as a predictor of coronary events in four racial or ethnic groups. N Engl J Med 358:1336-1345

13. Schmermund A, Möhlenkamp S, Stang A et al (2002) Assessment of clinically silent atherosclerotic disease and established and novel risk factors for predicting myocardial infarction and cardiac death in healthy middle-aged subjects: rationale and design of the Heinz Nixdorf Recall study. Risk factors, evaluation of coronary calcium and lifestyle. Am Heart J 144:212-218

14. Budoff MJ, Nasir K, McClelland RL et al (2009) Coronary calcium predicts events better with absolute calcium scores than age-sex-race/ethnicity percentiles: MESA (Multi-Ethnic Study of Atherosclerosis). J Am Coll Cardiol 53:345-352
15. Kälsch H, Lehmann N, Möhlenkamp S, Hammer C, Mahabadi AA, Moebus S, Schmermund A, Stang A, Bauer M, Jöckel KH, Erbel R (2012) Prevalence of thoracic aortic calcification and its relationship to cardiovascular risk factors and coronary calcification in an unselected population-based cohort: The Heinz Nixdorf Recall Study. Int $\mathbf{J}$ Cardiovasc Imaging. doi: 10.1007/s10554-012-0051-3

16. Wong ND, Gransar H, Shaw L et al (2009) Thoracic aortic calcium versus coronary artery calcium for the prediction of coronary heart disease and cardiovascular disease events. JACC Cardiovasc Imaging 2(3):319-326

17. Takasu J, Budoff MJ, O'Brien KD et al (2009) Relationship between coronary artery and descending thoracic aortic calcification as detected by computed tomography: the Multi-Ethnic Study of Atherosclerosis. Atherosclerosis 204(2):440-446

18. Budoff MJ, Nasir K, Katz R et al (2011) Thoracic aortic calcification and coronary heart disease events: the multi-ethnic study of atherosclerosis (MESA). Atherosclerosis 215(1):196-202

19. Santos RD, Rumberger JA, Budoff MJ et al (2010) Thoracic aorta calcification detected by electron beam tomography predicts allcause mortality. Atherosclerosis 209(1):131-135

20. Jacobs PC, Prokop M, van der Graaf Y et al (2010) Comparing coronary artery calcium and thoracic aorta calcium for prediction of all-cause mortality and cardiovascular events on low-dose nongated computed tomography in a high-risk population of heavy smokers. Atherosclerosis 209(2):455-462 